universal and complete confidence of surgeons until further rivisections performed by Lister, Briicke, and others, showed that the smooth lining of the vessel was the chief factor in preventing coagulation, and that intravascular clots are tormed most readily when the lining of the vessel was ivjured and the blood ceased to move. Instead of timidly tying a loose knot for fear of injuring the vessel, the suryeon now ties a firm ligature so as to rupture its lining coat, or at, least to apply sufficient pressure to cut off its nutrition and thus cause its death in order to make a starting-point for the corgulation which must occur to secure its permanent closure.

Another great objection to the old ligatures was the delay ther caused in coming away. This wearied the surgeon and extansted the patient. 'The ligature was sometimes pulled away before its time, and this often gave rise to the muchdreaded secondary hæmorrhage. In counselling that the ligature be left alone, Petit adds the, remark, as a kind of consolation, that he finds them generally to zome away of themselves in about two or three months. Of this sort of annoyance we hear nothing now. Experiment on the lower animals has taught us the existence of the lymphatics and their absorbing power. Experiments upon living animals has shown us that this power of absorbing extends to such things as catgut, a material readily made into strong cords. Properly prepared catgut is therefore almost universally used as a ligature, the ends are cut off short, and the knot is left to be absorbed and never once thought of again.

And, lastly, the edges of the wound are brought together with stitches of silver wire, silk, catgut, horsehair, according to whether much or little traction or more or less coaptation is demanded. Undue tension, compression, gaping, and irregularity of the wounded part, are all avoided ; a means of exit for serous oozing, \&c., is provided by non-irritating trainage-tubes. The antiseptic dressings are applied carefully and exactly. Large tents, dossils of lint, rude compresses are not thought of. The aseptic wound heals without swelling or inflammation. No throb disturbs the patient's rest. No drop of pus comes from the cut surface. Fever, tetanus, pyæmia, second hæmorrhage, as well as the old dread of the bleeding during the operation, are all nearly forgotten.

To the minds of the surgeons of the last century such a method of operation and such a mode of healing would probably sugyest the longed-for magic remedies by means of which many hoped to replace the cauteries, caustics, compresses, and filthy dressings with which they strove to heal the open wounds of their exhausted and cachectic patients.

\section{THE RIDER'S SPRAIN.}

By HENRY MORRIS, M.A., F.R.C.S., SLRGEON TO, AND LECTURER ON SURGERY AT, THE MIIDDLESEX HOSPITAL.

A GOOD many of our national sports and amusements are known to give rise to certain accidents and particular morbid changes. Thus, "camping out" occasionally prorokes an enlargement of the bursa over the trochanter major, owing to the hardness of the ground upon which persons who go in for this luxury sometimes have to sleep. Rinking has frequently led to Pott's and Colles'fractures. Bicycling has been accused of inducing hernia in its derotees, as rowing has heart disease. Lawn tennis leads frequently to sprain of the knee, or of one of the muscles of the calf. Fractured clavicles and other accidents even of a fatal character are unfortunately too frequent in the hunting-field. I have, however, met with two classes of cases, neither of which are sufficiently well recognised at present--these I may call for the sake of convenience "the lawn tennis arm" and "the rider's thigh." The former is a sprain of the pronator radii teres muscle, and the latter of the adductor longus.

The lawn tennis arm is the result, I believe, of the frequent back stroke, whereby the forearm is brought into rapid and forcible pronation. The condition is slight swelling wich tenderness on firm pressure along the course of the pronator, and pain in bringing the muscle into action, but as a rule not otherwise. I have of late seen three such cases, and one gentleman said he had known of several lawn tenuis players affected in the same way. The symptoms soon disappear if the movements of pronation and supination are restricted for a few weeks, and the forearm is enveloped in an elastic bandage or a firm elastic webbing.

The rider's thigh or sprain occurs very frequently; so frequently, indeed, in a mild form that the surgical instrument maker is applied to for some remedial support, though the injury is not thought severe enough to consult the surgeon about it. It is caused generally by the horseman suddenly making a strong grip owing to bis horse rearing, shying, slipping, or unexpectedly taking a jump. In this way the adductors are sharply and forcibly brought into action; and some of the fibres of one of them, generally the adductor longus, yield at a short distance from their origin. The pain at the time of the injury is often very trivial, and not sufficient to cause the horseman to dismount; but subsequently more pain is felt in walking; rather severe pain attends the act of mount. ing, and still more severe, sometimes described as unbear able, pain is excited by gripping the horse. The area of pain is confined to the upper and inner side of the thigh close to the origin of the adductors, and firm pressare in this part increases the intensity of the pain. Mr. Hawksley the well-known instrument maker of Oxford-street, tel's me that during the last twelve years he has seen as many as seventy-five such cases, and as many as ten during the last winter. The accident generally happens to hunting men, is more frequent in tall men, and affects the right thigh more often than the left. For these mild cases Mr. Hawksley makes a long web or leather strap, from two to three inches broad, sometimes padded to localise the pressure. This strap is passed round the thigh and pelvis, like a spica or figure-of- 8 bandage, on the outside of the breeches, and is firmly fastened in front. The action of this strap is immediate, as the man can at once firmly grip his horse. Often the huntsman rides to the meet with the strap put on loosely and tightens it up when the hounds get away. In more severe cases the surgeon is consulted, blood is effused, and, if in a large quantity, passes tbrough the saphenous opening and the other numerous apertures in the fascia lata for vessels and nerves, and is thus extravasated beneath the superficial fascia of the thigh, groin, and scrotum; or, perhaps, the fascia, which is thinner over the adductor muscles than elsewhere, is itself ruptured. From these more severe sprains many men lose a season's hunting, but they are as a rule able to ride again after a period of rest and freedom from horse exercise.

I will give briefly the notes of two very severe cases of rider's sprain which during last autumn came under my notice. In Case 1 the whole of the effused blood was not absorbed, but became in part organised into a firm fibrous mass, almost as hard as bone. For this reason it is specially interesting, as it amplities the truth of $M$. Charcot's recent remarks on effusions of blood at the fold of the elbow (Rev. de Chir?. Sept. 10th, 1881)-i.e., such effusions are not always completely absorbed; the resulting swelling may be as large as an egg, and of cartilaginous or osseous hardness, though at first independent of the bone they may subsequen ly become attached to it; they remain stationary for a long time, and are but little affected by treatment; and finally they may give rise to errors of diagnosis, being mistaken for exostoses, or detached and displaced fragments of bone.

I am indebted to my friend, Mr. Court, of Staveley, for the notes of the following case.

CASE 1.--Mr. R. A — aged thirty-six, a farmer. On the 24th of March, 1881, whilst out hunting, his horse galloped through a bog, fell and rolled upon him, the saddle pressing against his luins. When first seen by $\mathrm{Mr}$. Court there was a large brawny swelling the size of a cheese plate over Scarpd's triangle ; the testes were swollen, the scrotum nearly black, and a hard ridge was felt in place of the spermatic cord. No fracture of the pelvis could be detected; he could move both legs freely; and got up from his bed and passed water without admixture of blood. The swelling in the right thigh became very intlamed, and had every appearance of suppurating, but at last it gradually subsided, leaving a hard gristly substance the size of a man's thumb, which was apparently attached deeply to the tissues below the inner end of Poupart's ligament. During the summer of 1881 the substance became harder and more prominent, and projected beneath the skin of the thigh like a piece of stray cartilage, but gave rise to no pain and very little inconvenience. Absurbents were applied to it for some months without any effect, and its condition remained exactly the same 
n.ti: Mret t. 10 r 0 t is rear, when Mr. A- was agaiu th uwn fin hi hores, fallngr violently uvon a hart

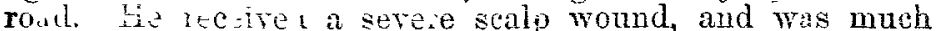
shakea. $\mathrm{U}_{\text {ton }}$ examining the swelling in the thigh, it was foumi to hive lecome quite flattened, and driven in, as it were, up:n tile deep siructures of the thigh, and for a fortnight MIr. Court th ught it would remain so; but gradually it resumed its former shape and size, and in June, 1882, it was as larre and prominent as it was twelve months ago. He can ride without any pain or trouble, the only inconvenience being a feeling of weakness in getting his leg into the stirrup.

On Sept. 20th, 1881, when Mr. Court brought this patient to me, there was a mass as hard as bone, and of the size and shape of a man's thumb when the last phalanx is fully flexed, situated at the inner and upper part of the right thighi.e., where the thigh joins the pubes and perineum, and over the origin of the long adductor muscle. It could not be made to move, and when seized between the finger and thumb gave me the impression of being connected by its own convex border with the body and ramus of the pubis. I was informed that it had been diagnosed by another surgeon as a portion of the pelvis fractured and displaced from its position beneath Puupart's ligament, downwards and inwards towards the perineum. But the condition of the patient when first seen after the accident, no less than the outlines of the pelvis months afterwards, was completely at variance with this opinion.

CASE 2.-A gentleman, aged forty-three, was sent to me by my friend Dr. Murray of Weymouth-street, on November $22 u d, 1881$, on account of an injury received whilst riding ten days previously. The horse reared, and the rider suddeviy gripping him felt something give way, and then immediately experienced a sensation as of something warm trick ling in to the flesh near the right groin. Much swelling and dis.olouration of the skin of the thigh and groin quickly followed, but had in great part disappeared before I was consulted. There still remained, however, some swelling near the junction of the thigh and perineum over the upper end of ihe long adductor tendon. Tenderness was caused by pressure, and severe pain was felt when the adductors were put into action. I ordered a spica webbing to be worn, which was made by Mr. Hawksley, at my direction, so as to resemble the body portion and one thigh, cut short, of a pair of drawers, padded sottly over the origin of the adductors. I also advised the patient to abstain from horse exercise for a few weeks. No other treatment was requisite.

\section{THE RIDER'S SPRAIN.}

\section{By EDWARD HENDERSON, M.D., F.R.C.S. EDIN.}

WHEN riding across a small water jump in the country, in the neighbourhood of Shanghai, the muscles on the inner side of my right thigh seemed suddenly to give way, and this sensation was attended by pain of so acute a character that I was for some minutes with diffieulty able to retain my seat in the saddle. On dismounting I found myself at once in a position of comparative ease, and soon discovered that, while a good de $x$ l of continuous dull aching was felt along the ins:de of the thigh, really acute pain only attended movements of adduction, such as are necessary to retain the seat securely on horseback. There was considerable tenderness along the course of the long adductor, and acute pain was experienced when pressure was made on the tendinous origin of that muscle, which had clearly been rather severely sprained. I am now (at the end of a week) almist free from pain in walking, but am still quite unable to ride.

This accident, which I have termed "rider's sprain," is, it would seem, of constant occurrence, and well known to horsemen. I have myself seen or heard of many cases of varying degrees of severity. The pain experienced at the moment of its occurrence is generally of a very acute character. One gentleman who sustained this injury when galloping, fainted after dismounting; the inside of his thigh became subsequently much discoloured, and he was for many weeks unable to mount a horse. Another showed such signs, of collapse that his companion, a surgeon, supposing he was ruptured, wisely rade the necessary examiuation on the spot. The point of greatest tenderness is apperently in all cases in the upper and inner part of the thigh, directly over the tendon of origin of the adductor longus muscle; but it is not, of course, to be supposed that the sprain is necessarily confined to a single division of the muscular mass concerned in the movement of adduction. A man who has once sustained this injury at all severely is liable to its recurrence, and in a few cases permanent weakness is left behind. In one example which came under my notice the sprain, a tolerably severe one, recurred twice in the same thigh, with an interval of some years. In another, the particulars of which were narrated to me, permanent weak ness resulted, the sufferer being compelled to give up horse exercise entirely. We suppose here that the accident may occur more frequently in riding China ponies than with full sized horses, on account of the difference of grip. A horseman who mounts a China pony for the first time usually experiences a sense of insecurity arising from the comparatively narrow clasp of his legs, and the small size of his mount in front of the saddle. When the rider and his horse have warmed to their work in crossing country, the accident seems less likely to occur, being more commonly met with when a fence or water jump is taken in cold blood, or at tlie beginning of a run; hence it is that this sprain is so frequently complained of as arising from an apparently trifling cause Some awkwardness in sitting or some unexpected movement of the horse is at the bottom of most cases. Time and rest will of course cure the greater number of these cases, but, in addition, a broad elastic bandage firmly applied over the upper part of the thigh and secured by a figure-of- 8 turn round the waist is, as I have myself found, of very material assistance at first in locomotion. A sporting friend tells me that stirrup leathers are sometimes used to support the injured muscles; they are turned twice round the upper part of the thigh and buckled on the outside; men who have once suffered from such a sprain, carrying their spare leather in the country in this way as a protection against a recurrence of the accident. The stirrup-leather can, of course, be easily slackened or tightened to suit the convenience of the wearer. A broad piece of girth-strap with double buckles would give a better support, and would have the advantage of some degree of elasticity. Doubtless the surgeon's instrument makers at home have been often called on to supply suitable supports in these cases.

I should myself like much to know whether the accident is really as common as $I$ am at present inclined to suppose it, and whether the peculiar seat of the cavalry soldier increases or diminishes his liability to this form of sprain. Sprains of the quadricep extensor muscle are specially referred to in some surgical text-books, but I have not yet come across any special notice of the same injury affecting the triceps adductor. Shanghai.

\section{MOTOR DIATHESIS OF THE SECONDARY PERCEPTIONS.}

\section{BY BRIGADE-SURGEON T. OUGHTON, A.M.D.}

SECONDARY perceptions are the subjective indices of the primary qualities existing in external entities-viz., position (distance and direction), dimensions (superficial and solid), magnitude, and motion. Irrefragable evidence has been offered by the eminent Locke, proving these qualities to be primary as affixed in natural objects; but he has failed in a recognition of the fact that, in the sensorial transformation from actualities to phenomena, the not infrequent crosswise action is now in exercise, whereby their mental equivalents can only be regarded as being secondary-that which is primary in the object becomes secondary in the perception. Neither will it be amiss to consider that here is precisely the block of error on which several systems of philosophy have stumbled, noteworthy among them being the ideational hypothesis of Berkeley and the intuitional conceptions of Kant. Medical philosophy scouts the Berkeleyan notion that the world is purely mental dynamics, neither does it accept the modification of Kant that the products of special 